\title{
A tentative study on security management based on dangerous goods road transportation
}

\author{
SHANG Yue \\ (Shandong Jiaotong University, Jinan 250023, China)
}

\begin{abstract}
The paper conducts analysis on the causes of dangerous goods road transportation accidents by applying analytic technique of security system science - Event Tree Analysis (ETA). By computing minimum cut and minimal path set of event tree and the important level of elementary event, the paper elicits the results that the factors of causing road transportation accident are multiple and its hazard is great while the paper also elicits the sorting of structural important level of elementary event. The paper offers the security countermeasures for dangerous goods road transportation which plays a vital role in safeguarding dangerous goods road transportation security.
\end{abstract}

Key words: dangerous goods transportation; event tree analysis technology; transportation security

\section{Introduction}

Dangerous goods refers to the goods which have the characteristics of explosion, burning, contamination, radiation and causticity and in the process of loading, unloading, transportation and storage which can easily cause bodily injury, property damage and (or) environmental contamination that need special protection.

In the evening on March 29th, 2005, one tank truck semitrailer driving on Beijing-Shanghai Highway had an accident in the section of Huai'an in Jiangsu province, which causes the leaking of liquid chlorine on the tank, the death of 29 person and the evacuation of more than 10,500 villagers and the direct economic loss amounts to more than 17 million Yuan.

At 19:00 on February 2008, a tank truck with the license plate number: Yu R16273, loading 29.97 tons of liquid nitrotoluenes (the required loading is 28 tons), when driving at $471 \mathrm{KM}$ location from Hunan section on Beijing-Zhuhai Highway, has overtaking collision with one huge passenger car with the license plate number: Xiang H91199, causing the leaking and burning of liquid nitrotoluenes, there are 15 deaths, 17 of them injured and two missing.

\section{Analysis on the causes of dangerous goods road transportation}

Through the analysis on recent years of dangerous goods road transportation accidents, the causes for the accidents mainly fall into the following categories:

(1) The causes of governmental departments in charge and relevant management departments

Some passengers or drivers illegally carry flammable and explosive dangerous goods to the bus. No harsh implementation of the national dangerous chemicals security management laws and regulations, ignoring the requirement for dangerous goods transportation accreditation certification, equating dangerous goods

SHANG Yue, associate professor of Shandong Jiaotong University; research field: transportation management. 
transportation with general goods transportation. Distemperedness of company's dangerous chemicals transportation system.

(2) Man's mistake

According to one's identifications, human's mistake can be summarized into four categories: mistake from the loading person, the attendants, the drivers and the maintenance person. Mistake from the drivers refers to peccancy driving or mistake. Mistake from the drivers is as follows: fatigue driving; or poor driving skills; no cautious driving, absent-mindedness, excessive high-speed driving; peccancy driving or overtaking; improper choices on driving routes, peccancy driving through densely populated area; peccancy hitchhiking irrelevant person, peccancy mix passengers with cargo, carrying dangerous goods on passenger car. Mistake from the maintenance person mainly consists of the following: no good maintenance for automobiles, no cautious checking to enable defective and trouble prone automobiles drive on the road; welders violate regulations to hotwork and maintain automobiles with dangerous goods in flammable and explosive circumstances.

(3) Defectiveness of facilities and establishment

Defectiveness of facilities and establishment can be divided into three categories: dangerous chemical containers on the vehicle or defectiveness of fixed packaging for dangerous chemicals; defectiveness of road establishment under the vehicle (includes road facilities and railway road junction); defectiveness of the vehicle itself (mainly includes braking, steering system, driving system, engines, etc.).

(4) Environmental causes

They include weather, landform, crowd, time, etc... The weather condition includes sunny, overcast, snow, wind, fog, hot and cold, etc. Landform and road condition affect automobile locomotion and drivers' view, while road condition also affects the disposal of dangerous goods leakage. The density of population affects the result of the accident. Time mainly refers to daytime or night, which affects drivers' driving and surrounding people's activities.

(5) Traffic accidents lead to dangerous goods accidents

Under this circumstance, traffic accident refers to the following two categories: one is the cars' collision, the other is automobile's self overturn or collision on some other things.

(6) Improper accident succor leads to ampliative calamities

Of the above-mentioned dangerous chemical transportation accidents, some are caused by improper succor which again leads to ampliative calamities.

According to the above analysis, dangerous goods highway transportation event tree chart can be devised. (Please refer to Fig. 1).

\subsection{Event tree minimum cut analysis}

Minimum cut refers to the cut set of necessary minimum limit for the upper-level incidents to occur. Every minimum cut is one possibility for the upper-level incident to occur. The more minimum cut, the more possibilities for the upper-level incident to occur, and the more minimum cut, the more dangerous for the whole system. By minimum cut, we can intuitively and roughly make out those which of the incidents occur most dangerously and which are lesser and which can be overlooked. We also know how to take countermeasures to reduce the probability of incident occurring. By applying Boolean algebra, the event tree structure function can be educed as follows:

$\mathrm{T}=\mathrm{A}_{1} \mathrm{~A}_{2} \mathrm{~A}_{3}=\left(\mathrm{X}_{1}+\mathrm{X}_{2}\right)\left(\mathrm{B}_{1}+\mathrm{B}_{2}+\mathrm{B}_{3}+\mathrm{B}_{4}\right)\left(\mathrm{X}_{27}+\mathrm{X}_{28}+\mathrm{X}_{29}+\mathrm{X}_{30}\right)=\left(\mathrm{X}_{1}+\mathrm{X}_{2}\right)\left(\mathrm{X}_{3}+\mathrm{X}_{4}+\mathrm{X}_{5}+\ldots+\mathrm{X}_{26}\right)\left(\mathrm{X}_{27}+\mathrm{X}_{28}+\mathrm{X}_{29}+\mathrm{X}_{30}\right)$

From the above format, we can see that event tree has 192 minimum cuts, that is, $\left\{X_{1}, X_{3}, X_{27}\right\}$, 
$\left\{X_{1}, X_{4}, X_{27}\right\}, \ldots\left\{X_{2}, X_{26}, X_{30}\right\}$. This demonstrates that the passes leading to dangerous goods transportation accident are numerous and the fatalness of conducting dangerous goods transportation accidents is great.

\subsection{Event tree minimal path set analysis}

Minimal path set refers to the path set of necessary minimum limit for the upper-level incidents not to occur. If the basic incident of the minimal path set is not likely to occur, then the upper-level accident is also not likely to occur. The more the minimal path set, the safer system is. After the education of the minimal path set, we know that there are a few possible plans for the upper-level incident not to occur, thus providing basis for controlling accidents. Generally speaking, controlling the fewness incident minimal path set is more favorable. The education of minimal path set is to apply its duality with minimum cut. Firstly, we draft the duality of event tree—success tree, that is, changing the AND gate of event tree into OR gate and vice versa and the occurring incidents into non-occurring. By applying the above-mentioned method, the minimum cut of success tree is educed and then changed into the minimal path set of event tree, the structure function of success tree is as follows:

$$
\mathrm{T}^{\prime}=\mathrm{A}_{1}{ }^{\prime} \mathrm{A}_{2}{ }^{\prime} \mathrm{A}_{3}{ }^{\prime}=\mathrm{X}_{1}{ }^{\prime} \mathrm{X}_{2}{ }^{\prime}+\mathrm{X}_{3}{ }^{\prime} \mathrm{X}_{4}{ }^{\prime} \mathrm{X}_{5}{ }^{\prime} \mathrm{X}_{26}{ }^{\prime}+\mathrm{X}_{27}{ }^{\prime} \mathrm{X}_{28}{ }^{\prime} \mathrm{X}_{29}{ }^{\prime} \mathrm{X}_{30}{ }^{\prime}
$$

Therefore, the minimal path set of event tree can be educed as follows: $\left\{X_{1}, X_{2}\right\},\left\{X_{3}, X_{4}, X_{5}, X_{26}\right\}, \ldots\left\{X_{27}, X_{28}\right.$, $\left.\mathrm{X}_{29}, \mathrm{X}_{30}\right\}$, which illustrates that there are three passes for the prevention of dangerous goods road transportation accident.

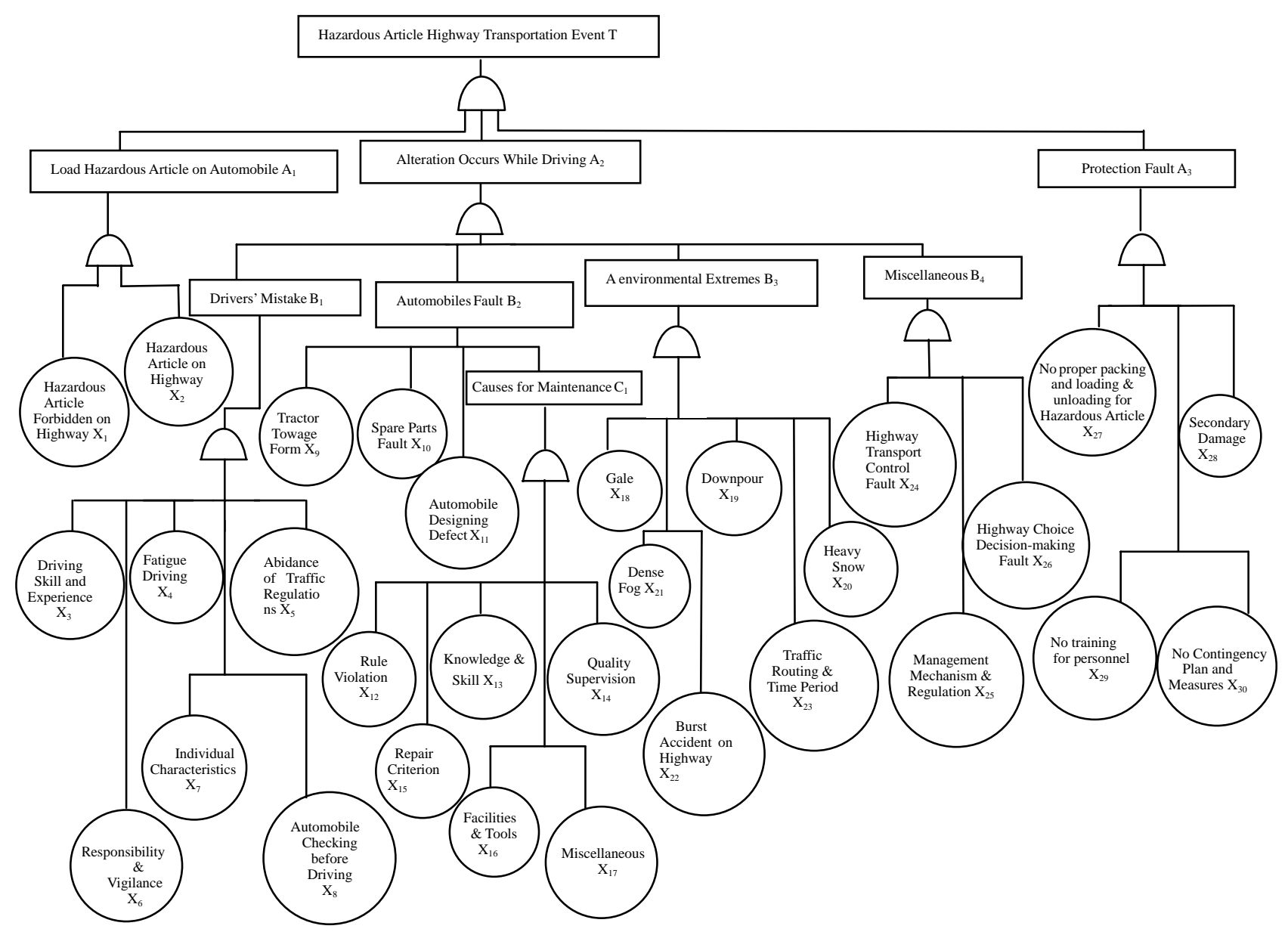

Fig. 1 Dangerous goods highway transportation event tree chart 


\subsection{Structural importance level analysis of event tree}

Structural importance level modulus reflects the importance level of elementary events from the perspective of event tree structure, which provides basis for system security designers to choose parts reliability and improve system structure. Suppose the probability for each elementary event to occur is the same, according to the simplified computation of structural importance level, structural importance level sequence of elementary events can be educed as follows:

$$
\mathrm{I}(1)=\mathrm{I}(2)>\mathrm{I}(4)=\mathrm{I}(5)=\ldots=\mathrm{I}(26)>\mathrm{I}(27)=\mathrm{I}(28)=\mathrm{I}(29)=\mathrm{I}(30)
$$

This demonstrates that $X_{1}, X_{2}$ the upper-level events most, elementary events $X_{27}, X_{28}, X_{29}, X_{30}$ take second places while elementary events $\mathrm{X}_{3}, \mathrm{X}_{4}, \mathrm{X}_{5} \ldots \mathrm{X}_{26}$ influence the least.

\section{Countermeasures for dangerous goods road security transportation}

By the above analysis, this current event tree has three minimal paths set, that is, no transportation for dangerous goods; prevention on the substantial changes of automobile driving condition; excellent protection measures. Theoretically speaking, if we can control whichever minimal path set not to occur, we can avoid the upper-level event, that is, dangerous goods road transportation accidents. In addition, we know from the analysis of structural importance level that the importance level of elementary events $X_{1}, X_{2}$ is the greatest, that is, to ensure that passengers or drivers should not carry flammable and explosive goods without peccancy and should transport dangerous goods according to procedures. After the overall consideration, the following counter-measures should be taken:

(1) Strictly control dangerous goods transportation qualifications, enhance publicity and educational training (TAN De-rong, 2003).

(2) Carry out drivers' resources management, enhance training to avoid mistake. Through the effective use of various resources (hardware, software, facility and human), we can safely and effectively fulfill the tasks. The training mainly covers:

- Attention management-By applying all kinds of methods and skills to improve drivers attention distribution ability and prevent them from absent-mindedness;

- Drivers management-Improve drivers' ability to properly understand all kinds of responsibilities;

- Stress management To control the life-style and working conditions which are likely to lead to fatigue and affect health and then security;

- Attitude management-To control and redress all kinds of bad attitudes, conceptions and behavior style which are likely to cause driving dangers;

- Risk management-To conduct quantitative and qualitative analysis and evaluation on the danger data to ensure safe driving to the maximum.

(3) Enhance system security and strengthen system mistake-prevention and mistake-tolerance capabilities

System security is the basic viewpoint of modern security science. From the perspective of man-made factors, relying solely on drivers to ensure transportation safety is far from enough, the close coordination of resources such as automobile maintenance, commerce, traffic management, operating is greatly needed. For example the environmental factors in event tree analysis require management departments' vigorous assistance to avoid the accident to occur. Conducting analysis on the causes of traffic accident, only around $30 \%$ is man-made factors while around $70 \%$ comes from organization factors. From the minimum cut, we can see that the passes leading to 
dangerous goods highway transportation accidents are numerous. Therefore, in order to reduce traffic accident ratio, we should focus on the overall security system of the organization.

Establishing system security above all, laws and regulations construction should be strengthened. Security regulations are the basis and guarantee for safe production management and operation. Whether security regulations are perfect, scientific and up-to-standard, whether they can be observed with consciousness in the process of operation are the vital indications of system security.

Establishing system security requires security education being strengthened. Generally speaking, man's understanding for the objective world always lags behind the development of mistakes, so does security consciousness. As far as dangerous goods transportation is concerned, conducting training and education on dangerous goods is of vital importance. For anyone who is involved as to dangerous goods has to be trained concerning some relevant knowledge, let alone the person who is directly involved in the transportation, loading and unloading and storing of dangerous goods. They should not only learn the basic knowledge of dangerous goods, such as classification, characteristics and packaging of dangerous goods, but also grasp the urgent countermeasures for dangerous goods accidents.

The key for establishing system security is to develop system mistake-prevention and mistake-tolerance capabilities. Practices prove that adopting single measure is hard to effectively improve driving security level. Only from the perspectives of laws, regulations, management, procedures and training to conduct all-round comprehensive prevention, thus can prevention works ensure excellent effect.

\section{References:}

TAN De-rong. (2003). Security decision-making of dangerous goods transportation. Comprehensive Transportation.

WU Zong-zhi. (2004). Dangerous goods highway transportation risk analysis \& evaluation methodology research. Applied Basics \& Engineering Science Journal.

(Edited by Joy and Chris)

\section{(continued from Page 45)}

Peter R. Dickson. (1982, Fall). Person-situation: Segmentation’s missing link. Journal of Marketing, 46(4), 56-64.

Philip. Kotler. (2001). Marketing management. MEI Ru-he. Trans. Beijing: China Renmin University Press.

Thedore. Levitt. (1980). Marketing success through differentiation of anything. Harvard Business Review, USA: Free Press, 1-30.

Tony Lunn. (1986). Segmenting and constructing markets. In: Robert M. Worcester \& John Down Ham. (Eds.). Consumer market research handbook (3rd revised and enlarged ed.). Elsevier Science Publishers. B. V., 87-423.

Wedal, Michel \& Wagwr Kamakura. (2000). Market segmentation, conceptual and methodological foundations (2nd ed.). Boston: kluwer, USA.

Wendell. R. Smith. (1956). Product differentiation and market segmentation as alternative marketing strategies. Journal of Marketing, 21, 3-8.

Wilkie, William L. \& Joel B. Cohen. (1977). A behavioral science look at market segmentation research. Moving A Head With Attitude Research. In: Yoram Wind. (Ed.). Chicago: American Marketing Association.

Yoram Wind. (1978, August). Issues and advances in segmentation research. Journal of Marketing Research, 317- 337.

ZHANG Hong-ji \& SANG Yin-feng. (2002). The rising of the after-marketing management concept. Business Economics and Management, (10).

(Edited by Joy and Chris) 